\title{
Effect of stable and fluctuating temperatures on the life history traits of Anopheles arabiensis and An. quadriannulatus under conditions of inter- and intra-specific competition
}

\author{
Craig Davies ${ }^{1,2^{*}}$, Maureen Coetzee ${ }^{1,2}$ and Candice L. Lyons ${ }^{1,2,3}$
}

\begin{abstract}
Background: Constant and fluctuating temperatures influence important life-history parameters of malaria vectors which has implications for community organization and the malaria disease burden. The effects of environmental temperature on the hatch rate, survivorship and development rate of Anopheles arabiensis and An. quadriannulatus under conditions of inter- and intra-specific competition are studied.

Methods: The eggs and larvae of laboratory established colonies were reared under controlled conditions at one constant $\left(25^{\circ} \mathrm{C}\right)$ and two fluctuating $\left(20-30^{\circ} \mathrm{C}\right.$ and $\left.18-35^{\circ} \mathrm{C}\right)$ temperature treatments at a ratio of 1:0 or 1:1 (An. arabiensis: An. quadriannulatus). Monitoring of hatch rate, development rate and survival was done at three intervals, 6 to $8 \mathrm{~h}$ apart depending on developmental stage. Parametric ANOVAs were used where assumptions of equal variances and normality were met, and a Welch ANOVA where equal variance was violated $(a=0.05)$.

Results: Temperature significantly influenced the measured life-history traits and importantly, this was evident when these species co-occurred. A constant temperature resulted in a higher hatch rate in single species, larval treatments $(P<0.05)$. The treatment $18-35{ }^{\circ} \mathrm{C}$ generally reduced survivorship except for An. arabiensis in mixed, larval species treatments where it was similar to values reported for $25^{\circ} \mathrm{C}$. Survivorship of both species at $20-30{ }^{\circ} \mathrm{C}$ was not significantly impacted and the adult production was high across species treatments. The development rates at $25^{\circ} \mathrm{C}$ and $20-30{ }^{\circ} \mathrm{C}$ were significantly different between species when reared alone and in mixed species from larvae and from eggs. The effect of temperature was more pronounced at $18-35^{\circ} \mathrm{C}$ with An. arabiensis developing faster under both competitive scenarios and An. quadriannulatus slower, notably when in the presence of its competitor $(P<0.05)$.

(Continued on next page)
\end{abstract}

\footnotetext{
* Correspondence: craig.davies13@gmail.com

${ }^{1}$ Wits Research Institute for Malaria, Faculty of Health Sciences, University of the Witwatersrand, Johannesburg, South Africa

${ }^{2}$ Vector Control Reference Laboratory, Centre for Opportunistic, Tropical and

Hospital Infections, National Institute for Communicable Diseases,

Sandringham, Johannesburg, South Africa

Full list of author information is available at the end of the article
} 
(Continued from previous page)

Conclusions: The influence of temperature treatment on the development rate and survival from egg/larvae to adult differed across species treatments. Fluctuating temperatures incorporating the extremes influence the key life-history parameters measured here with An. arabiensis outcompeting An. quadriannulatus under these conditions. The quantification of the response variables measured here improve our knowledge of the link between temperature and species interactions and provide valuable information for modelling of vector population dynamics.

Keywords: Anopheles arabiensis, Anopheles quadriannulatus, Community ecology, Competition, Development rate, Life-history, Survival, Temperature

\section{Background}

Increases in average temperatures predicted for the African continent [1] are expected to influence the malaria transmission landscape [2] by affecting key lifehistory parameters of vector species [3]. Ambient water temperatures can affect a number of traits of the aquatic stages of mosquitoes, in turn influencing adult recruitment [3] and the malaria disease burden. In addition, biological interactions result in nonlinear responses by shifting the competitive landscape to favour one species over another, thereby influencing species abundance and diversity [4]. Across the malaria transmission landscape in Africa, diurnal temperature changes can range between 5 to over $20{ }^{\circ} \mathrm{C}[5,6]$ and these are set to increase in magnitude, notably in maximum temperature extremes in southern Africa [1].

As poikilothermic organisms, the development and survival of mosquitoes is closely tied to the external environment. Temperature conditions influence certain life-history traits, such as survivorship, directly through its impact on larval survival and the resultant adult output as well as indirectly by affecting adult longevity. For instance, temperatures above $30{ }^{\circ} \mathrm{C}$ have been shown to decrease adult survival and negatively impact the adult emergence rate by reducing larval survival in Anopheles gambiae (s.s.) [3]. Several parameters within malaria/ mosquito dynamics are influenced to some degree by temperature, including: the probability of infection of the Anopheles vector by the Plasmodium malaria parasite and therefore, the likelihood of transmission; the rate of infection in the local human population; and equally as importantly, the relative emergence rate of vectors [7]. Defining the temperature-related parameters and quantifying the biological response of malaria vectors, specifically life-history traits, provides valuable information for modelling of vector population dynamics and contributes to our understanding of the factors which determine the malaria disease burden [8].

In north-eastern South Africa, significant distribution overlap exists between the malaria vector An. arabiensis Patton and the non-vector An. quadriannulatus Theobald, both sibling species of the An. gambiae complex, and which are morphologically indistinguishable [9].
Across the African continent however, An. arabiensis shows a much broader distribution compared to $A n$. quadriannulatus, evident in the absence of the latter species in places such as Madagascar and West Africa $[9,10]$. The so-called An. "quadriannulatus" in Ethiopia has been shown to be a closely related but distinct species, An. amharicus [11], which shares the same polytene chromosomal arrangements and occurs where mean annual rainfall is above $1,000 \mathrm{~mm}$ [9]. Anopheles arabiensis favours transient pools exposed to sunlight which show significant temperature variation throughout the day $[12,13]$. Although observed temperature field data for larvae of An. quadriannulatus is sparse, its presence in the same breeding habitats as $A n$. arabiensis in the region [14] suggests that as larvae these species may be ecological equivalents, at least in the region where they occur sympatrically. Distribution modelling showing the absence of An. quadriannulatus over much of Africa where An. arabiensis appears, has been suggested to be under the influence of topography and climate on the former species which likely inhabits areas where the average mean temperature is below the predicted $26.7^{\circ}$ $\mathrm{C}$ average for $\mathrm{An}$. arabiensis, while the latter appears less affected by these environmental variables [15].

Survival of An. gambiae complex members from egg to adult requires a development strategy which takes into account the short lived nature of the breeding site and the ability of the larvae to tolerate temperature extremes. In addition to such abiotic conditions, biotic interactions exist which occur when immatures sharing a breeding habitat come into frequent contact and compete for space and resources [16-18]. The influence that older instar larvae have on con- and hetero-specifics, through cannibalism and predation respectively, significantly reduce survival in sibling species of the An. gambiae complex [16, 19]. The presence of a competitor may also have an influence on the age at pupation and An. arabiensis larvae have been shown to pupate a day earlier than An. gambiae (s.s.) in mixed species treatments suggesting a more rapid development rate at a constant temperature of $27{ }^{\circ} \mathrm{C}$ [16]. When immatures are reared under higher temperatures $\left(>30{ }^{\circ} \mathrm{C}\right)$ the production of $A n$. arabiensis adults is greater than $A n$. 
gambiae (s.s.), although overall production drops as temperatures approach lethal limits [17]. Under semi-field conditions in Western Kenya, habitat sharing between An. arabiensis and An. gambiae was detrimental for the former with higher mortality rates and earlier time to pupation [18]. The outcome of these interactions is thus context dependent and changes in variables such as temperature, may shift the competitive landscape in favour of one species over another, thereby influencing species abundance and diversity [4]. Due to differences in the vectoral competency and behaviour of each species, changes in the community composition of vectors will have implications for malaria transmission and the resultant control interventions [20].

Considering the effect of temperature on the development and survivorship of anopheline immatures, most studies have been done at constant temperatures and under ideal laboratory conditions (e.g. $[16,17]$ but see [21]). Relying on extrapolations from these means may be unrealistic and daily temperature dynamics, in addition to means, influence mosquito biology and parasite transmission to a large degree [6, 21-23]. In addition, few studies have investigated the effect temperature has on species interactions in Anopheles. There is currently a paucity of information on the thermal biology of An. quadriannulatus and, importantly, what effect its co-occurrence with An. arabiensis has on the life history of immature forms of the latter species. The relationship between fluctuating temperatures and An. arabiensis larval development and survival in the presence of a competitor also remains unclear, and information on the effects of temperature on the larvae of these two species is valuable in light of competition with the vector species.

This study aimed to determine the outcome of interand intra-specific competition on the development rate and survival of An. arabiensis and An. quadriannulatus larvae by controlling ecological variables (competitive scenario and temperature); and to determine whether community composition in the adult stage is regulated by competition under constant and fluctuating abiotic conditions. Improving our knowledge of species interactions at the larval stage in response to increased temperature variability and temperature extremes contributes to our understanding of the current distributions and relative abundances of $A n$. arabiensis and $A n$. quadriannulatus in southern Africa.

\section{Methods}

\section{Mosquito colonies and maintenance}

Long-established colonies used in these experiments are housed in the Botha De Meillon Insectary at the Vector Control Reference Laboratory in Johannesburg, South Africa. The An. quadriannulatus colony, SANGWE, originated from Zimbabwe and has been reared in the laboratory since 1998, whilst the An. arabiensis colony, AMAL, originates from the Kruger National Park, South Africa and was established in 2009. The An. quadriannulatus colony used in this study represents the designated species A which occurs south of the Zambezi River in southern Africa, in contrast to An. quadriannulatus species B known from the Ethiopian highlands [11]. The insectary is kept at a constant temperature of around $25{ }^{\circ} \mathrm{C}$ and relative humidity of approximately $80 \%$ with a photoperiod of $12 \mathrm{~h}$ light to $12 \mathrm{~h}$ dark and simulated dawn/dusk periods of $30 \mathrm{~min}$. Larval stages of all colonies are reared on a mixture of ground Beeno ${ }^{\circ}$ dog biscuits and yeast extract, while adults are provided with a $10 \%$ sugar solution.

\section{Experimental design}

Adult cages of each colony were provided with a darkened Petri dish serving as an egg plate and females were allowed to oviposit following two blood meals to ensure successful completion of the gonotrophic cycle [24]. The egg plates were left in the cages for six $h$ to minimise variance in hatching. Eggs and recently hatched and unfed larvae $(<24 \mathrm{~h}$ old $)$ of each species were transferred into separate temperature treatments using a pipette with $1 \mathrm{~cm}$ cut off the tip. Forty larvae or eggs (comprising single species treatments, or a 1:1 ratio of $A n$. arabiensis to An. quadriannulatus) were introduced into $500 \mathrm{ml}$ containers with distilled water $\left(25^{\circ} \mathrm{C}\right)$ such that the surface area was $175 \mathrm{~cm}^{2}$ to maintain a standard density of larvae. Each temperature treatment was replicated five times, randomly assigned in the incubator and switched around daily.

The eggs/larvae were reared under fluctuating temperature regimes mimicking those most likely to exist under natural conditions [12] and which have been shown to be development thresholds in the laboratory [17, 23]: (1) $20-30{ }^{\circ} \mathrm{C}$ and (2) $18-35{ }^{\circ} \mathrm{C}$ (Panasonic MIR154 Cooled Incubator, Gunma, Japan); or at a constant temperature of $25{ }^{\circ} \mathrm{C}$ in the insectary. Within the range of temperature treatment (1) the development rate of $A n$. arabiensis has previously been shown to be linear becoming non-linear above $32{ }^{\circ} \mathrm{C}$ [23] with no development occurring at $15{ }^{\circ} \mathrm{C}$ and the upper maximum temperature of $(2)$ at $35{ }^{\circ} \mathrm{C}$. Daily light:dark cycles in the incubator were set on a 12:12 $\mathrm{h}$ regime cycling from $12 \mathrm{am}$ to $12 \mathrm{pm}$ as in the insectary. Temperatures were set to peak during the day light hours and lower temperatures set to occur during the dark cycle. Larvae in all treatments received optimal amounts of food according to their instar stage. Monitoring of egg hatch and emergence of adults was done at three intervals, six to eight hours apart depending on developmental stage. Adults were collected and killed using ethyl acetate, and the individuals 
stored in eppendorf tubes with silica for preservation purposes. The rearing conditions and experimental procedure follows closely that of Lyons et al. [23].

Polymerase Chain Reaction (PCR) was used to distinguish between adults from treatments where there was interspecific competition. DNA from the leg or wing from the preserved adults was isolated following standard PCR protocol outlined in Scott et al. [25] using a Bio-Rad Thermal Cycler C1,000 (Hercules, USA). DNA isolates of An. arabiensis (AMAL) and An. quadriannulatus (SANGWE) were used as controls in PCR and gel electrophoresis.

\section{Statistical analysis}

Survivorship to the adult stage was measured as the proportion of adults that emerged from the initial number of eggs or larvae used in each treatment. Hatch rate of eggs and development rate analyses were conducted on the time it took for $50 \%$ of the eggs to hatch and $50 \%$ adult emergence, respectively. This approach effectively removed late adult emergence outliers. Rates were calculated as rate $\left(\right.$ days $\left.^{-1}\right)=1 /$ ( $t$ to $50 \%$ life stage/24). No distinction could be made between the hatch times of the two species when in mixed species treatments as the larvae are morphologically identical.

Shapiro-Wilk's and Levene's tests were used to assess assumptions of normality and homogeneity of variances, respectively, in SPSS version 20 (IBM Inc., Chicago, USA). When both assumptions were met, a parametric two-way fixed-effect ANOVA was conducted to test the effect of constant and fluctuating temperatures on egg hatch rate, survivorship and development rate followed by the post-hoc Tukey HSD test. A fixed effects ANOVA was chosen above a random effects ANOVA because there were less than 5 levels of each factor being tested [26]. In cases where the assumption of homogeneity of variances was rejected, a Welch test was employed using the Games-Howell post-hoc test for unequal variances [27].

\section{Results \\ Larval treatments}

There was a significant effect of temperature $\left(\mathrm{F}_{(2,48)}=\right.$ 35.122, $P<0.05)$ and species $\left(\mathrm{F}_{(3,48)}=6.650, P<0.05\right)$ treatment on mean survivorship of first-instar larvae to adulthood (Fig. 1). Anopheles arabiensis tolerated higher temperatures better, and An. quadriannulatus survival was lower when in the presence of its sibling species at the more extreme temperature treatment. When $A n$. arabiensis and An. quadriannulatus are combined, interspecific competition resulted in reduced survivorship for each species at $18-35{ }^{\circ} \mathrm{C}$ and $25^{\circ} \mathrm{C}$, respectively. Neither species experienced a reduction in survival at $20-30{ }^{\circ} \mathrm{C}$ irrespective of the competitive scenario. In single species treatments at $18-35{ }^{\circ} \mathrm{C}$, survivorship was negatively affected.

The effect of temperature on larval development differed in each competitive scenario. There was a significant effect of temperature $\left(\mathrm{F}_{(2,48)}=181.181, P<0.05\right)$ and species $\left(\mathrm{F}_{(3,48)}=25.097, \quad P<0.05\right)$ treatment on

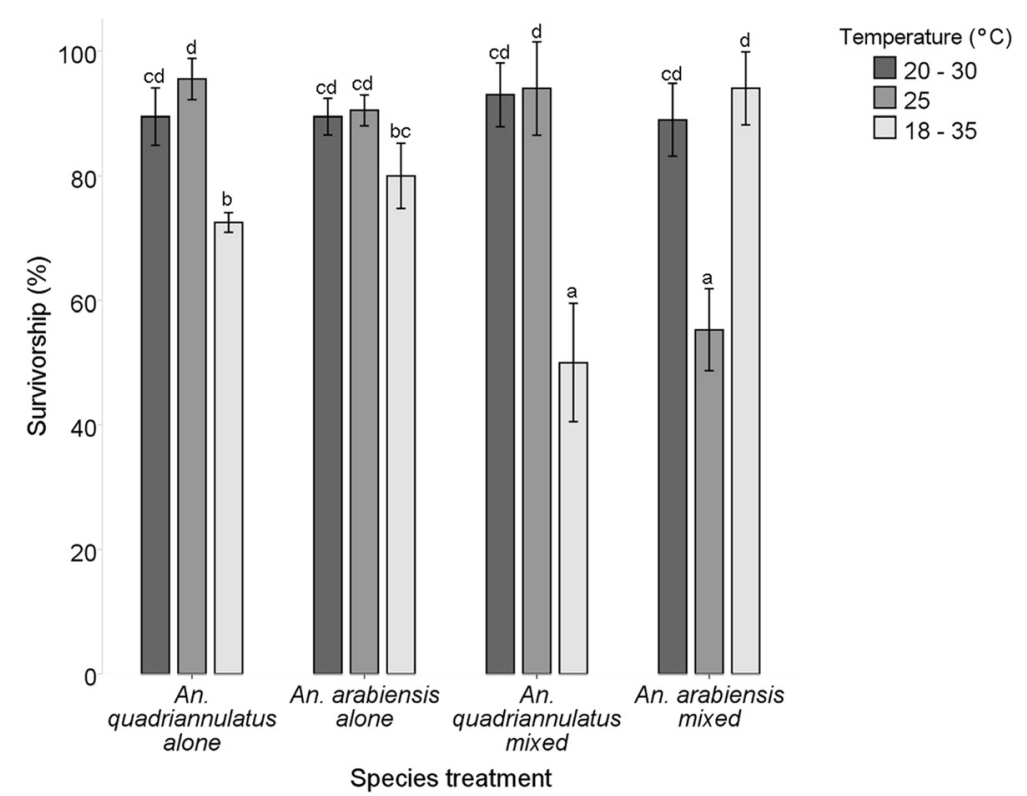

Fig. 1 Survivorship (\% $\pm 95 \% \mathrm{Cl}$ ) of first-instars to adults in single species and mixed species treatments of An. arabiensis and An. quadriannulatus at the two fluctuating temperatures $\left(20-30^{\circ} \mathrm{C}\right.$ and $\left.18-35^{\circ} \mathrm{C}\right)$ and a constant temperature of $25^{\circ} \mathrm{C}$. Lower case letters indicate where significant differences in mean survivorship for each group lie (Tukey HSD, $P<0.05$ ) 
development rate from larvae to adults. A significant interaction was also observed between the independent variables: temperature and species treatment $\left(\mathrm{F}_{(6,48)}=\right.$ 51.342, $P<0.05$ ) (Fig. 2). Anopheles arabiensis adults developed faster at the greater fluctuating temperature and emerged sooner (12.67 days in single and 13.45 days in mixed species treatments) compared to An. quadriannulatus (14.1 days in single and 13.75 days in mixed species treatments). At $20-30{ }^{\circ} \mathrm{C}$ the development rate profiles in single and mixed species were similar, increasing when a species' heterospecific was present. Across the different temperature treatments, An. arabiensis showed the same development response when in mixed species treatments (Fig. 2).

\section{Egg treatments}

When reared alone, the response of hatch rates to temperature treatments were similar between the two species, being fastest at $25{ }^{\circ} \mathrm{C}\left(\mathrm{F}_{(2,36)}=16.704, P<0.05\right)$ (Tukey HSD, $P<0.05$ ). In interspecific treatments there was no significant difference at $25{ }^{\circ} \mathrm{C}\left(0.536\right.$ days $\left.^{-1}\right)$ in hatch rate compared to $18-35{ }^{\circ} \mathrm{C}\left(0.556\right.$ days $\left.^{-1}\right)$. The temperature treatment $20-30{ }^{\circ} \mathrm{C}$ resulted in the longest time to hatch in all treatments regardless of competitive scenario. In mixed species treatments it was not possible to distinguish between the eggs and first-instars of the two different species, and for this reason, they were lumped together for analysis purposes.
There was a significant effect of temperature $\left(\mathrm{F}_{(2,48)}=\right.$ 17.940, $P<0.05)$ and species $\left(\mathrm{F}_{(3,48)}=16.199, P<0.05\right)$ treatment on mean survivorship from eggs to adults (Fig. 3). A significant interaction was observed between the temperature and species treatment and survivorship $\left(\mathrm{F}_{(6,48)}=22.046, P<0.05\right)$. When An. arabiensis and $A n$. quadriannulatus were reared alone, the number of adults emerging from the initial cohort of eggs was significantly lowered in the temperature treatment $18-35^{\circ}$ C. In interspecific treatments, survival was higher for An. arabiensis at $18-35{ }^{\circ} \mathrm{C}$ and for An. quadriannulatus at $20-30{ }^{\circ} \mathrm{C}$. Survival rates were similar for both species at $25{ }^{\circ} \mathrm{C}$ in interspecific treatments when reared from egg to adult (Fig. 3). Survival of An. arabiensis in mixed species treatments at $18-35{ }^{\circ} \mathrm{C}$ and $20-30{ }^{\circ} \mathrm{C}$ was similar.

The development rate of An. arabiensis in mixed species treatments was significantly faster and the adults emerged sooner across all temperature treatments, while for An. quadriannulatus it was slower when reared alone at $18-35{ }^{\circ} \mathrm{C}$ (Tukey HSD, $P<0.05$ ) (Fig. 4). Generally, development rates were slightly slower, regardless of competitive scenario, at $18-35^{\circ} \mathrm{C}$ and at $20-30{ }^{\circ} \mathrm{C}$, while the mean development rates of each species were higher at a constant $25^{\circ} \mathrm{C}$ (Fig. 4).

\section{Discussion}

Comparing the hatch times, survivorship and development rates of immatures to adults of the vector, Anopheles

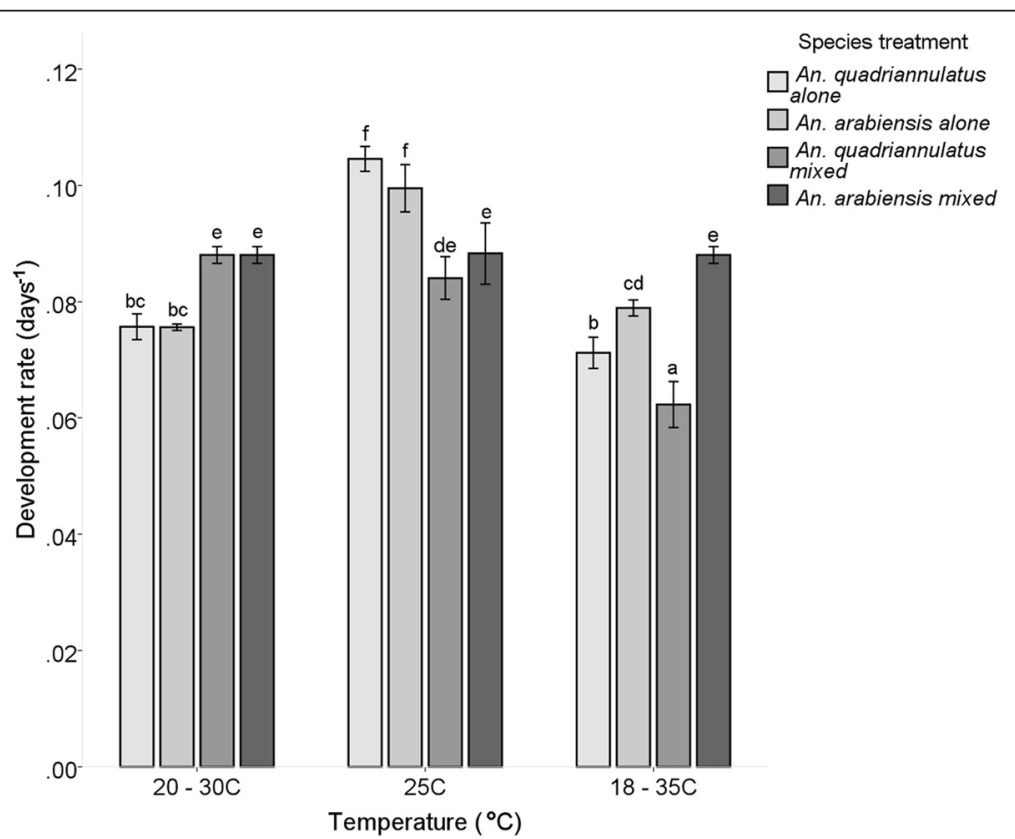

Fig. 2 Development rate (days ${ }^{-1} \pm 95 \% \mathrm{Cl}$ ) of first-instar larvae to $50 \%$ of the adult population in single species and mixed species treatments of An. arabiensis and An. quadriannulatus, at three temperature treatments $\left(20-30^{\circ} \mathrm{C}, 25^{\circ} \mathrm{C}\right.$ and $\left.18-35^{\circ} \mathrm{C}\right)$. Differences in lower case letters indicate significant differences in mean development rate for each group (Tukey HSD, $P<0.05$ ) 


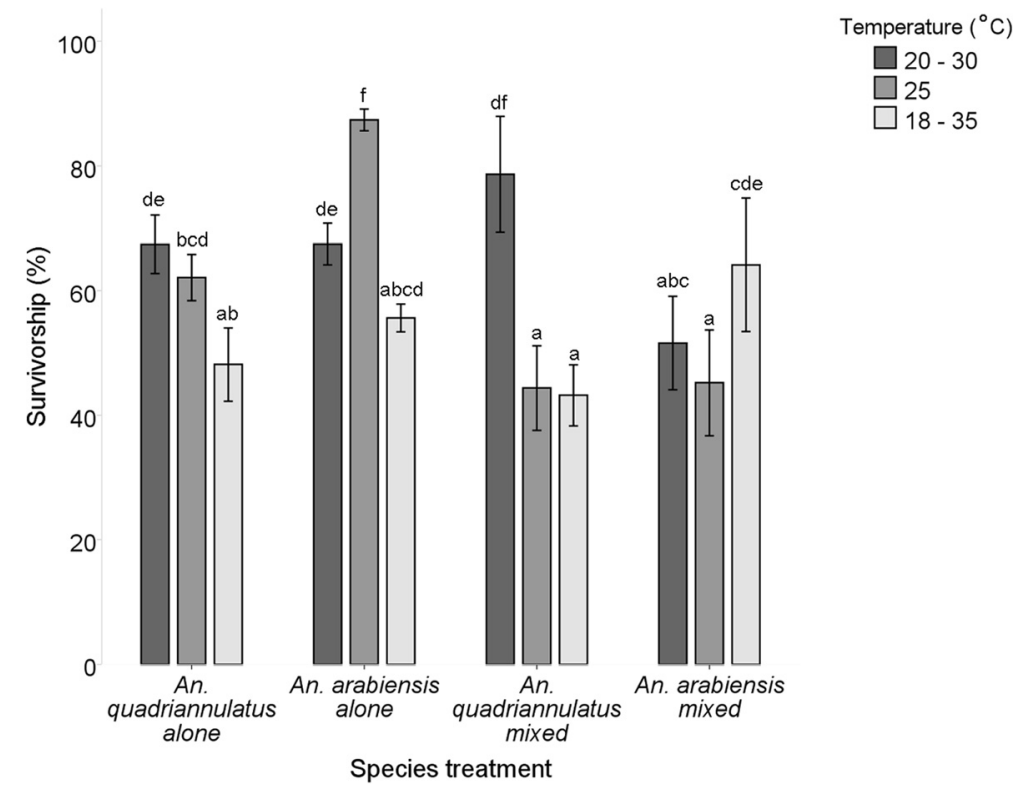

Fig. 3 Survivorship (\% $\% 2 S E, 95 \% \mathrm{Cl})$ of eggs to adults in single species and mixed species treatments of An. arabiensis and An. quadriannulatus at the two fluctuating temperatures $\left(20-30^{\circ} \mathrm{C}\right.$ and $18-35^{\circ} \mathrm{C}$ ) and a constant temperature of $25^{\circ} \mathrm{C}$. Differences in lower case letters indicate significant differences in mean survivorship for each group (Tukey HSD, $P<0.05$ )

arabiensis (AMAL strain), and non-vector, An. quadriannulatus (SANGWE strain), we found different responses to both fluctuating and constant temperatures in single and mixed species treatments. Importantly, these effects were evident when these species co-occurred, with responses in the variables measured being influenced by the presence of a heterospecific. A constant temperature resulted in a higher hatch rate in single species treatments. The treatment $18-35{ }^{\circ} \mathrm{C}$ generally reduced survivorship except for An. arabiensis in mixed, larval species

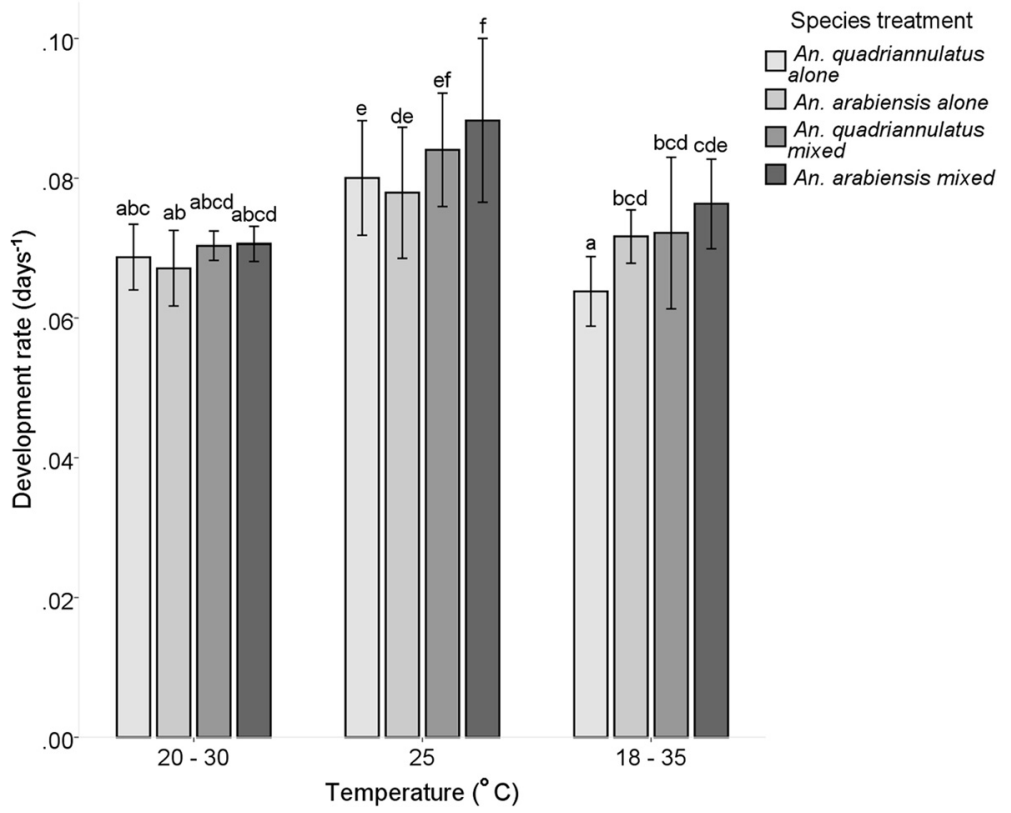

Fig. 4 Development rate (days ${ }^{-1} \pm 2$ SE, $95 \%$ Cl) of the eggs that survived to adulthood ( $50 \%$ of the adult population) in single species and mixed species treatments of An. arabiensis and An. quadriannulatus at three temperature treatments $\left(20-30{ }^{\circ} \mathrm{C}, 25^{\circ} \mathrm{C}\right.$ and $\left.18-35^{\circ} \mathrm{C}\right)$. Differences in lower case letters indicate significant differences in mean development rate for each group (Tukey HSD, $P<0.05$ ) 
treatments where it was similar to values reported for $25^{\circ}$ C. Survivorship of both species at $20-30{ }^{\circ} \mathrm{C}$ was not significantly impacted and the adult production was high across species treatments. The development rates at $25^{\circ} \mathrm{C}$ and $20-30{ }^{\circ} \mathrm{C}$ differed between species when reared alone and in mixed species from larvae and from eggs. The effect of temperature was more pronounced at $18-35{ }^{\circ} \mathrm{C}$ with $\mathrm{An}$. arabiensis developing faster under both competitive scenarios and An. quadriannulatus slower, notably when in the presence of its competitor.

Although hatching typically took place within three days, some eggs only hatched after a week. However, the majority of the larvae that hatched did so within the first four to five days, a finding supported in An. arabiensis [28] and An. gambiae (s.s.) [29]. When eggs are exposed to more extreme temperatures for longer periods (relative to the temperature of the rest of the regime), development of the larva inside the egg can be constrained, whereas exposure to brief periods of these same extremes would not be as detrimental [30]. These variations result in staggered hatching amongst egg batches which may be beneficial when the conditions at the breeding site are unpredictable, or when predators/pathogens are present that could be detrimental to the entire egg batch $[28,29]$.

Survivorship values differed greatly in the current study, with $80-90 \%$ of the first-instar larvae of An. arabiensis surviving to adulthood across the temperature treatments and only falling below $60 \%$ when in mixed treatments at $25{ }^{\circ} \mathrm{C}$. Survivorship of An. arabiensis was highest when reared in mixed species treatments at 20$30{ }^{\circ} \mathrm{C}$ and $18-35{ }^{\circ} \mathrm{C}$. When An. arabiensis and An. gambiae (s.s.) larvae are reared together at a constant $35{ }^{\circ} \mathrm{C}$, the former species dominates, although overall survival is reduced compared to $25{ }^{\circ} \mathrm{C}$ [17]. At $25{ }^{\circ} \mathrm{C}$, An. gambiae (s.s). survival is $20 \%$ higher than that of $A n$. arabiensis [16, 17], an observation also observed by Paaijmans et al [18] under semi-field conditions in Kenya. In the current study, the high survival rate of larvae to adults in mixed species treatments of $A n$. arabiensis (94\%) compared to An. quadriannulatus (50 \%) at $18-35{ }^{\circ} \mathrm{C}$ suggest the superior competitiveness of the former species over the latter species at more extreme temperatures [17]. This observation reflects our current understanding of at least An. arabiensis in Africa which is known to increase in abundance, relative to An. gambiae (s.s.), during the months of the year with the highest maximum air temperatures [24], and which occurs in regions such as the Ethiopian Rift Valley [31] where water temperatures may reach highs too extreme for An. gambiae (s.s.) larvae. When reared from eggs, adult survival rates were comparable to those found by Schneider et al. [16] and Kirby \& Lindsay [17] in studies on larval competition. At a constant $25^{\circ} \mathrm{C}$, An. quadriannulatus is the superior competitor (94\%) over An. arabiensis (55\%) in mixed species, larval experiments. In comparison, survivorship was equal when reared at $25{ }^{\circ} \mathrm{C}$ from eggs. Lower survival values were also reported in An. arabiensis single and mixed species [with An. gambiae (s.s.)] treatments at this constant temperature [17]. Higher constant temperatures of $30{ }^{\circ} \mathrm{C}$ and $35{ }^{\circ} \mathrm{C}$ have been shown to lead to reduced survival rates for both species, although survival of $A n$. arabiensis was higher than $A n$. gambiae (s.s.) [17]. At $20-30{ }^{\circ} \mathrm{C}$ larval survival rates did not differ markedly across species treatments in the current study. However, survival from egg to adult was higher in An. quadriannulatus than An. arabiensis at this fluctuating temperature.

Where An. arabiensis and An. quadriannulatus were reared alone, the significant reduction in survival rates at $18-35{ }^{\circ} \mathrm{C}$ may also be attributed to increasing environmental stress on An. arabiensis and An. quadriannulatus, as the temperatures that the larvae are exposed to for a proportion of the time are not favourable for survival [23]. Temperature variations in the small, often temporary, water bodies in which the larvae of these species exist [12, 13], may show significant temporal variation and are generally not stratified by depth [32] Exposure to extreme temperatures in species that inhabit temporary, small sites is common. As such, tolerance of higher temperatures compared to anopheline species that occupy larger, more permanent sites, such as An. funestus, is important. At this temperature regime, deaths were increasingly common when fourthinstar larvae pupated, as well as in failed eclosion of pupae into adults (pers. obs.), an observation supported by Bayoh \& Lindsay [33] in An. gambiae (s.s.) above $30^{\circ}$ C. One explanation for the failed metamorphosis to pupae and then to adult is that raised temperatures heighten the development rate $[23,33]$ demanding more rapid uptake of nutrients and a quicker metabolism [34], requirements which may be physiologically demanding, resulting in insufficient mass being accumulated for eclosion [35].

The development rates at $25{ }^{\circ} \mathrm{C}$ and $20-30{ }^{\circ} \mathrm{C}$ were significantly different between species when reared alone and in mixed species from larvae and eggs. Earlier emergence was reported at $25^{\circ} \mathrm{C}$ and at $20-30{ }^{\circ} \mathrm{C}$ in single species treatments. No difference in development rate was seen between species in mixed treatments. The effect of temperature was more pronounced at 18$35{ }^{\circ} \mathrm{C}$ with An. arabiensis developing faster under both competitive scenarios and An. quadriannulatus slower, especially when in the presence of its competitor. When reared from eggs, development rates at the two fluctuating temperatures were generally similar. Notable differences in time to eclosion between $A n$. arabiensis and An. gambiae (s.s.) under competition and 
different water temperatures, with the latter species consistently emerging sooner, have been reported [17, 18]. These findings have been attributed to the larger adult size of $A n$. arabiensis which requires greater mass accumulation and thus a longer time spent acquiring resources as immatures $[16,17]$. The comparable development rates in the current study suggest the requirements for growth are similar for each species investigated here under the constant $25^{\circ} \mathrm{C}$ and the fluctuating $20-30{ }^{\circ} \mathrm{C}$ temperature regimes. At $18-35{ }^{\circ} \mathrm{C}$, environmental temperature may have a significant stress effect on the time to adult emergence especially for An. quadriannulatus regardless of the presence of its competitor species. The observation in $A n$. arabiensis that there is no significant negative effect of fluctuating temperatures incorporating a maximum extreme on development time likely explains the occurrence of this species in drier and warmer conditions, such as northern Botswana, where An. quadriannulatus is absent [9].

Habitat sharing by the larvae of these two species would not be detrimental on the development rate of either at moderate temperature conditions, and in fact, may benefit immatures of each as they emerge sooner compared to when reared alone, avoiding the risk that the aquatic habitat will dry up. However, as adults tend to be smaller when emerging sooner [36] their fitness may be diminished and adult longevity reduced [37]. The potential advantages for mosquito larvae to developing faster is an earlier release from threats from competitors, predators and pathogens [38] and potential loss of habitat through habitat flushing, from excessive rainfall [39], or drying up.

Interference competition, leading to insufficient nutrient acquisition, and predation are possible causes of reduced survival and slow development of An. quadriannulatus at high temperatures $[16,35]$. Interestingly, the more rapid development of $A n$. arabiensis at high temperatures did not lead to reduced adult emergence either through failed pupation or eclosion, as has been hypothesised by Chambers \& Klowden [35] in Aedes and used to explain similar observations in An. gambiae (s.s.) by Bayoh \& Lindsay [33]. At a constant $25^{\circ} \mathrm{C}, A n$. quadriannulatus appears to exert a predatory effect on $A n$. arabiensis survival but not development rate. Predatory behaviour by $A n$. quadriannulatus is reported by Koenraadt \& Takken [19] as fourth-instars of this species were observed to prey on An. gambiae (s.s.) first-instar larvae. A mix of different instar stages in a treatment may thus result in predation by one species, which appears to be a facultative process in $A n$. quadriannulatus, dependent on temperature.

Improving our understanding of the abiotic parameters influencing malaria vector population dynamics is necessary for modelling malaria transmission. The findings of differential physiological responses to temperature and competitive scenario reported here have implications for understanding the malaria disease burden, especially in the light of high temperature extremes and temperature variability predicted as a result of climate change [1]. However, the limitations of a controlled study need to be considered and semifield trials will help elucidate better the influence of changing biotic and abiotic variables on the competitive interactions and population dynamics of malaria vectors. It is important to note that these effects are context dependent and that smaller, transient pools may have higher rates of competition compared to larger water bodies where, for instance, predators may have a greater impact on community organisation of adult Anopheles species [4]. Moreover, future investigations on larval interactions may wish to determine the influence these conditions have on malaria epidemiology by studying transmission probabilities and other characteristics of anopheline vectors such as adult body size. While such recommendations for future research are admittedly broad, the findings of this study nonetheless give us an insight into the outcome of biotic interactions between closely related species under variable temperatures, important in community ecology terms, and vital for understanding vector-borne disease epidemiology in a given region.

\section{Conclusions}

The current distributions and relative abundances of An. arabiensis and An. quadriannulatus in southern Africa are unlikely to be influenced by changing species interactions in response to increased temperature variability associated with a warming climate [2]. If high temperature extremes, such as the $18-35{ }^{\circ} \mathrm{C}$ investigated here were to become commonplace and extend over a number of weeks, the increased survival and negative effect $A n$. arabiensis has on An. quadriannulatus where these two occupy the same breeding sites, would favour the former's survival and could alter the vector borne disease burden as a result of increased adult recruitment. Survivorship of both species at 20$30{ }^{\circ} \mathrm{C}$ was not significantly impacted and adult production was high across species treatments. However, the complexities of the effects of changing local conditions, such as temperature, on vector abundance do not only extend to the interactions between these two sympatric species and are an interplay between the influences of the human and ecological settings. Generally, more semi-field experiments are required to improve our understanding of the effects of competition and how this changes under different conditions. 


\section{Abbreviations}

ANOVA, analysis of variance; DNA, deoxyribonucleic acid; $\mathrm{PCR}$, polymerase change reaction; Tukey HSD, Tukey (Honest Significant Difference) post-hoc test

\section{Acknowledgements}

This project was funded by a DST/NRF South African Research Chair Initiative award to MC. CLL was supported by a SPARC fellowship through Wits University. Two anonymous referees are thanked for their comments and suggestions.

\section{Authors' contributions}

MC, CLL and CD conceptualised the study. CD conducted the experiments and analysed the data. CD wrote the first draft and all the authors approved the final version.

\section{Competing interests}

The authors declare that they have no competing interests.

\section{Author details}

${ }^{1}$ Wits Research Institute for Malaria, Faculty of Health Sciences, University of the Witwatersrand, Johannesburg, South Africa. ${ }^{2}$ Vector Control Reference Laboratory, Centre for Opportunistic, Tropical and Hospital Infections, National Institute for Communicable Diseases, Sandringham, Johannesburg South Africa. ${ }^{3}$ Present address: Plant Protection Research (PPR), Agricultural Research Council, Vredenburg, Stellenbosch, South Africa.

\section{Received: 4 December 2015 Accepted: 7 June 2016}

\section{Published online: 14 June 2016}

\section{References}

1. New M, Hewitson B, Stephenson DB, Tsiga A, Kruger A, Manhique A, et al. Evidence of trends in daily climate extremes over southern and west Africa. J Geophys Res. 2006;D14102.

2. Tonnang HE, Kangalawe RY, Yanda PZ. Review: Predicting and mapping malaria under climate change scenarios: the potential redistribution of malaria vectors in Africa. Malar J. 2010;9:1.

3. Christiansen-Jucht CD, Parham PE, Saddler A, Koella JC, Basáñez MG. Larval and adult environmental temperatures influence the adult reproductive traits of Anopheles gambiae s.s. Parasit Vectors. 2015:8:1.

4. Juliano SA. Species interactions among larval mosquitoes: context dependence across habitat gradients. Ann Rev Entomol. 2009:54:37-56.

5. Minakawa N, Omukunda E, Zhou G, Githeko A, Yan G. Malaria vector productivity in relation to the highland environment in Kenya. Am J Trop Med Hyg. 2006;75:448-53.

6. Pascual M, Dobson AP, Bouma MJ. Underestimating malaria risk under variable temperatures. Proc Nat Aca Sci. 2009;106:13645-6.

7. Killeen GF, MCKenzie FE, Foy BD, Schieffelin C, Billingsley PF, Beier JC. A simplified model for predicting malaria entomologic inoculation rates based on entomologic and parasitologic parameters relevant to control. Am J Trop Med Hyg. 2000;62:535-44.

8. Parham PE, Pople D, Christiansen-Jucht C, Lindsay S, Hinsley W, Michael E. Modeling the role of environmental variables on the population dynamics of the malaria vector Anopheles gambiae sensu stricto. Malar J. 2012;11:271.

9. Coetzee M, Craig M, le Sueur D. Distribution of African malaria mosquitoes belonging to the Anopheles gambiae complex. Parasitol Today. 2000;16:74-7.

10. Pock-Tsy JML, Duchemin JB, Marrama L, Rabarison P, Le Goff G, Rajaonarivelo V, Robert V. Distribution of the species of the Anopheles gambiae complex and first evidence of Anopheles merus as a malaria vector in Madagascar. Malar J. 2000;2:33.

11. Coetzee M, Hunt RH, Wilkerson R, Della Torre A, Coulibaly MB, Besansky NJ. Anopheles coluzzii and Anopheles amharicus, new members of the Anopheles gambiae complex. Zootaxa. 2013;3619:246-74.

12. Gillies MT, Coetzee M. A supplement to the Anophelinae of Africa south of the Sahara (Afrotropical region), vol. 55. Johannesburg: Publications of the South African Institute for Medical Research; 1987. p. 115-7.

13. Gimnig JE, Ombok M, Kamau L, Hawley WA. Characteristics of larval anopheline (Diptera: Culicidae) habitats in Western Kenya. J Med Entomol. 2001;38:282-8

14. Davies C, Coetzee M, Lyons CL. Characteristics of larval breeding sites and insecticide resistance in the Anopheles gambiae complex in Mpumalanga, South Africa. Afr Entomol. 24:(in press).
15. Levine RS, Peterson AT, Benedict MQ. Geographic and ecologic distributions of the Anopheles gambiae complex predicted using a genetic algorithm. Am J Trop Med Hyg. 2004;70:105-9.

16. Schneider P, Takken W, McCall PJ. Interspecific competition between sibling species larvae of Anopheles arabiensis and An. gambiae. Med Vet Entomol. 2000;14:165-70

17. Kirby MJ, Lindsay SW. Effect of temperature and inter-specific competition on the development and survival of Anopheles gambiae sensu stricto and An. arabiensis larvae. Acta Trop. 2009;109:118-23.

18. Paaijmans KP, Huijben S, Githeko AK, Takken W. Competitive interactions between larvae of the malaria mosquitoes Anopheles arabiensis and Anopheles gambiae under semi-field conditions in western Kenya. Acta Trop. 2009:109:124-30.

19. Koenraadt CJM, Takken W. Cannibalism and predation among larvae of the Anopheles gambiae complex. Med Vet Entomol. 2003:17:61-6.

20. White GB. Anopheles gambiae complex and disease transmission in Africa. Trans Roy Soc Trop Med Hyg. 1974;68:278-98.

21. Maharaj R. Life table characteristics of Anopheles arabiensis (Diptera: Culicidae) under simulated seasonal conditions. J Med Entomol. 2003:40:737-42.

22. Paaijmans KP, Blanford S, Bell AS, Blanford JI, Read AF, Thomas MB. Influence of climate on malaria transmission depends on daily temperature variation. Proc Nat Aca Sci. 2010;107:15135-9.

23. Lyons CL, Coetzee M, Chown SL. Stable and fluctuating temperature effects on the development rate and survival of two malaria vectors, Anopheles arabiensis and Anopheles funestus. Parasit Vectors. 2013;6:104.

24. Clements AN. The Physiology of Mosquitoes. New York: The MacMillan Company; 1963. p. 412-5.

25. Scott JA, Brogdon WG, Collins FH. Identification of single specimens of the Anopheles gambiae complex by the polymerase chain reaction. Amer J Trop Med Hyg. 1993;49:520-9.

26. Bolker BM. Linear and generalized linear mixed models. In: Ecological statistics: Contemporary theory and application. U.S.A: Oxford University Press; 2015. p. 309-30.

27. Field A. Discovering statistics using IBM SPSS statistics. London: Sage Publications; 2013.

28. Yaro A, Dao A, Abamou A, Crawford JE, Gwadz R, Traore SF, Lehmann T. The distribution of hatching time in Anopheles gambiae. Malar J. 2006:5:19.

29. Kaiser ML, Koekemoer LL, Coetzee M, Hunt RH, Brooke BD. Staggered larval time-to-hatch and insecticide resistance in the major malaria vector Anopheles gambiae S form. Malar J. 2010;9:360.

30. Impoinvil DE, Cardenas GA, Gihture Jl, Mbogo CM, Beier JC. Constant temperature and time period effects on Anopheles gambiae egg hatching. J Am Mos Cont Ass. 2007;23:124-30.

31. Mekuria Y, Petrarca V, Tesfamariam T. Cytogenetic studies on the malaria vector mosquito Anopheles arabiensis Patton in the Awash Valley, Ethiopia. Parassitol. 1982;24:237-43.

32. Paaijmans KP, Jacobs AFG, Takken W, Heusinkveld BG, Githeko AK, Dicke M, Holtslag AAM. Observations and model estimates of diurnal water temperature dynamics in mosquito breeding sites in western Kenya. Hydro Proc. 2008;22: 4789-801.

33. Bayoh MN, Lindsay SW. Effect of temperature on the development of the aquatic stages of Anopheles gambiae sensu stricto (Diptera: Culicidae). Bull Entomol Res. 2003:93:375-81.

34. Korochkina SE, Gordadze AV, Zakharkin SO, Benes H. Differential accumulation and tissue distribution of mosquito hexamerins during metamorphosis. Ins Biochem Mol Bio. 1997;27:813-24.

35. Chambers GM, Klowden MJ. Correlation of nutritional reserves with a critical weight for pupation in larval Aedes aegypti mosquitoes. J Am Mos Cont Ass. 1990;6:394-9.

36. Lyimo EO, Takken W, Koella JC. Effect of rearing temperature and larval density on larval survival, age at pupation and adult size of Anopheles gambiae. Entomol Exp Applic. 1992;63:265-71.

37. Ameneshewa B, Service MW. The relationship between female body size and survival rate of the malaria vector Anopheles arabiensis in Ethiopia. Med Vet Entomol. 1996;10:170-2.

38. Service MW. Population dynamics and mortalities of mosquito preadults. In: Lounibos LP, Rey JR, Frank JH, editors. Ecology of mosquitoes: Proceedings of a workshop. Vero Beach: Florida Medical Entomology Laboratory; 1985. p. 185-201.

39. Paaijmans KP, Wandago MO, Githeko AK, Takken W. Unexpected high losses of Anopheles gambiae larvae due to rainfall. PLoS One. 2007:2:e1146. 